\title{
Oecophylla Smaragdina (Hymenoptera: Formacidae) and Odontotermes sp. (Isoptera: Termitidae) a Potential Source of Antioxodant: The Two Most Preferred Edible Insects of Arunachal Pradesh, India
}

\section{Mohsin Raza}

Rajiv Gandhi University

Sonam Drema Tukshipa

Rajiv Gandhi University

Jharna Chakravorty ( $\sim$ jharnargu@gmail.com )

Rajiv Gandhi University

\section{Research Article}

Keywords: Oecophylla Smaragdina, Hymenoptera, Odontotermes sp., Isoptera, Antioxodant, Edible Insects

Posted Date: November 11th, 2021

DOI: https://doi.org/10.21203/rs.3.rs-1057539/v1

License: (9) This work is licensed under a Creative Commons Attribution 4.0 International License.

Read Full License

Version of Record: A version of this preprint was published at Discover Food on January 6 th, 2022. See the published version at https://doi.org/10.1007/s44187-021-00005-1. 


\section{Abstract}

Antioxidant potential of weaver ant Oecophylla smaragdina (adult \& brood) and termite odontotermes $s p$, the two common species of insects used as food by tribes of Arunachal Pradesh and elsewhere in India. Our findings highlight the antioxidant potential of these two insects. DPPH scavenging activity IC50 $(\mu \mathrm{g} / \mathrm{ml})$ ranged from 59.559 (ant adult) to 66.30 (termite). Termite species scored higher ABTS scavenging activity (IC50: $\mu \mathrm{g} / \mathrm{ml})$, Ferric reducing power (TPEE $\mu \mathrm{g} / \mathrm{g})$ and phenols (mg GAE/g) $(18.70$, 36.60 and 626.92) than weaver ant adult $(52.57,211.21$ and 369.69) and ant brood $(33.34,114.32$, 486.04). On the other hand, ant adult scored higher flavonoid (mg RTE/g) (663.4) than its brood (387.2) and termite species (58.0). Ant brood contained substantial amounts of phenols and flavonoid, comparatively higher than phenols of ant adult and flavonoid of termite. These two insects may serve as an ideal dietary food supplement for handling oxidative stress and as replacement for some conventional food products. However, further study is needed to find out the bio-active compound at individual species level.

\section{Introduction}

Antioxidants are substances that can prevent or slowdown the damage to cell caused by free radical, produced in the body as a reaction to environmental or other pressures. In the past decade, antioxidant compounds have gained acceptance among the general public for their ability to neutralize reactive and damaging form of free radicals. Although insects are known for their diverse nutritional properties, high percentage of protein and/or high content of fatty acids (mono and polyunsaturated), minerals and vitamins, however, contribution of insects as functional food (i.e.; to provide both basic nutrition and health benefit) is still too scarce. Henry (2010) suggested that it is essential to evaluate and assess functional benefits of food to provide evidence based science to substantiate health benefits.[1] Keeping this in mind the present investigation was aimed to evaluate the antioxidant potential of most preferred edible insects i.e.; weaver ant and termite.

Among the tribe of Arunachal Pradesh, entomophagy is a traditional and culturally accepted practice. The interest in the use of insects as food in this state has been reported in several earlier studies [2][3][4][5][6] and has revealed 102 edible species of insects belonging to 13 different orders taken as food by one or the other 26 major tribes of Arunachal Pradesh.[7] Two kinds of edible insect, weaver ants (O. smaragdina Fabricius 1775) and termites (Odontotermes $s p$.) are appreciated by virtually all tribes of the region. We found that the main reason behind the wide acceptance of these two insects, apart from their taste and flavour that they were locally abundant throughout the year (weaver ant) and they could be gathered in large amounts during their swarming periods (termites). Ant and termite have been known for long time to be popular food insects not only in Arunachal Pradesh, but also in many parts of the world [8][9][10] [11] including other parts of India.[7] Given this widespread acceptance of these two kind of insects as human food, except for our investigation on nutrient content analyses [6], no detailed information on antioxidant activity of the Indian species have been published to date except a very preliminary investigation by Raza et al. [12] Ever since, ants as well as termites depend on nearby food sources that 
are influenced by climatic factors, mineral content of the soil and vegetation in their respective geographical areas, etc. Therefore, the present investigation is the extension of our earlier study on taking into account of species collection only from a selected area of Arunachal Pradesh. Our study on the antioxidant potential of these insects, nevertheless, demonstrates that these two insects might serve as an ideal dietary food supplement for handling oxidative stress and as replacement of some conventional food products.

\section{Material And Methods}

\section{Sample Collection and Identification}

Odontotermis sp. (termite) and weaver ant, 0 . smaragdina (weaver ant) were collected from Emchi village (Papumpare district, Arunachal Pradesh). Termite was collected at night and ant (adult and brood) were collected from nest on the mango tree. The sexes of the specimens were not separated, because both are equally appreciated as food. All the specimens were taken to the laboratory of Rajiv Gandhi University in chilled freeze-boxes. The insects were taxonomically identified in the laboratory, confirmed by the Zoological Survey of India, Kolkata as Oecophylla smaragdina Fabricius 1775 (Hymenoptera, Formicidae) and Odontotermes sp. (Isoptera, Termitidae). Once in the laboratory the sampled insects were washed thoroughly in double distilled water and brought them to dryness and stored at $-20^{\circ} \mathrm{C}$.All the analysis were performed within a months' time. All the solvents and chemicals used in the study were of analytical grade. The analyses were done for the parameter: ABTS (2,2'-azino-bis 3-ethylbenzothiazoline6-sulfonic acid radical cation), DPPH (2,2-di(4-tert-octylphenyl)-1-picrylhydrazyl radical), Ferric Reducingpower, phenolic and flavonoids.

\section{Extraction procedure}

$10 \mathrm{~g}$ each of chopped insect sample was homogenized in $50 \mathrm{~mL}$ of buffered methanol (1 mM PBS buffer $\mathrm{pH} 7.2$ ) kept in orbital shaker for 48 hours. The resultant extract was centrifuged at $7000 \mathrm{rpm}$ for 30 minutes at $4{ }^{\circ} \mathrm{C}$. The supernatant was concentrated under vacuum evaporator at $40^{\circ} \mathrm{C}$ to dryness and the dry residue was dissolved in buffered methanol for further analysis.

\section{Biochemical Analyses}

ABTS radical scavenging activity was determined by following the method Moore and Yu [13] with minor modification (for preparation of ABTS, instead of $\mathrm{H}_{2} \mathrm{O}_{2}, 2.6 \mathrm{mM}$ Potassium per-sulphate was used.

Further, ABTS was kept 24 hours of incubation at room temperature instead of 16 hours for final preparation of ABTS working solution). Trolox was used as standard and activity was expressed as IC50 value $(\mu \mathrm{g} / \mathrm{ml})$. DPPH radical scavenging activity was determined following the method Blois,[14] with minor modifications and using ascorbic acid as standard and expressed as IC50 value $(\mu \mathrm{g} / \mathrm{ml})$. FerricReducing power (FRP) was determined according to Oyaizu [15] with minor modification as described by 
Prieto et al. [16] using a Tocopherol as standard and expressed as TPE ( $\mu \mathrm{g} / \mathrm{g})$. Total phenolic and flavonoid content were measured following Singleton et al. [17] and Chang et al [18] respectively with minor modification. Gallic acid was used as standard for phenolic and Rutin for flavonoids and expressed as GAE equivalent (mg GAE/100g) and Rutin equivalent (mg RTE/100g) respectively.

Data analyses were performed in triplicate and expressed mean $\pm S D$, and the difference between mean were evaluated by one way-Analysis of variance (ANOVA) using Graph Pad Prism 9.0.0 (California Inc. US).

\section{Result And Discussion}

O. smaragdina, the weaver ant when required leafy nests that the ants construct are plucked from their host tree for consumption after sorting them out from the nest. Both larval and adult stages are preferred and are eaten either raw or turned into "chutney" by mixing them with spicy ingredients. On the other hand, Odontotermes sp. usually collected when it is abundant i.e.; during swarming phase during rainy season and is eaten either raw or roasted. Therefore, it is evident that compounds meant for antioxidant capacity are consumed without any loss of activity when consumed as fresh/raw. Our results (Table 1Figure 1 to 4) show that the antioxidant pattern of studied insects varied according to taxonomy and life stages.

Table 1

$\mathrm{ABTS} \cdot+$, DPPH $\bullet$ free radical scavenging activity $(\mathrm{IC} 50 \mu \mathrm{g} / \mathrm{ml})$, ferric-reducing power $(\mathrm{a}-\mathrm{TPEE} \mu \mathrm{g} / \mathrm{g})$, total flavonoids content (mg RTE/100g) and phenolic content (mg GAE/100g) of weaver ant and termite. Values are presented as mean $\pm S D(n=3)$ for each dataset.

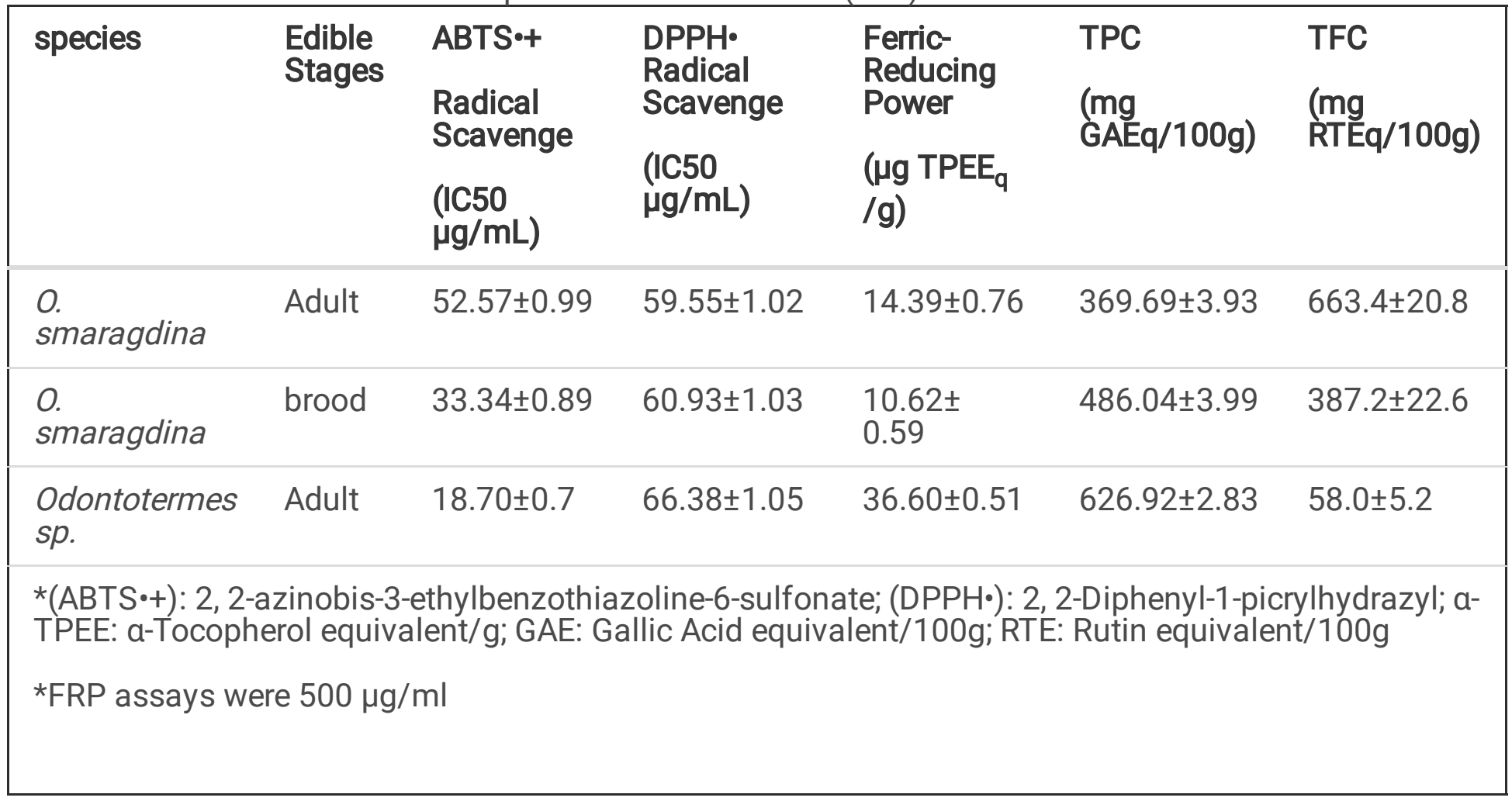


From the analysis Table 1 and Figure 1, it appears that termite better inhibit free radicals with low inhibitory concentrations (IC50) of 18.70 for ABTS followed by ant brood (33.34) ant adult 52.57. In turn antiradical activity against DPPH was noted in ant adult and its brood (59.55 and 60.93) with slightly lower in termite (66.38). These values are either superior or similar to some edible insects, common fruits and vegetable, though, in some cases better scavenging activity could be noticed (Fig. $2 \& 3$ ). Differences in radical scavenging activity between ant and termite in the present study and other reports from edible insects might be for their protein quality in respective species. Chatsuwan et al [20] postulated that protein from different species might give different scavenging activity on DPPH and ABTS. The strong inhibition of free radicals could be justified by the relatively high concentrations of total phenols and flavonoids quantified in this study. Phenolic compounds are known to be powerful compounds with ability to reduce free radicals. [22]

TFCS (Fig. 4) in the weaver ant adult was significantly $(P<0.05)$ higher in adult $(663.4)$ than its brood (387.2) while least was observed in the termite species (58.0 mg RTE/100g). These values (Fig, 2), except for termite, are higher than or similar to most of the fruits and vegetable with few exception. [25] Nevertheless, with the value 58.0, flavonoid content in termite is higher than vegetables like Amaranthus, S.nigram, B.campestris S. oleracea (values between 27.52 to 59.70 ) and fruits (A. gigantum, A. muricata, A. gensis, A. alboviolaceum, F. capensis, values between 23.36 to 36.86 ) reported by Tsiba et al [22].

TPC (mg GAE/g) (Fig. 5) was significantly higher $(P<0.05)$ in the termite species $(626.92)$ followed by the ant brood (486.04) and its adult (369.69). These values are superior to as reported for few edible insects and comparable to most of the fruits and vegetables, except for few.

The results obtained advocate that $O$. smaragdina and Odontotermes $s p$. can both be recommended as a source of natural antioxidants on par with or superior to conventional fruits and vegetables to avoid oxidative stress such as degenerative diseases [28] and provide protection against oxidation at the cellular level by interfering in enzyme activity.[29]

\section{Declarations}

\section{Data Availability}

The dataset generated for this study are available on request to the corresponding author.

\section{Acknowledgement}

The authors are thankful to the Department of Biotechnology, Government of India (DBTNER/Agri/24/2013; DBT-NER/95/SP42584/2021 dated 30th March 2021) for the financial support of this research through project grant to Dr. J. Chakravorty. Thanks are also extended to Rajiv Gandhi University, Arunachal Pradesh for providing the facilities to complete this report. 


\section{References}

1. C. J. Henry, “Functional foods," Eur. J. Clin. Nutr., vol. 64, pp. 657-659, 2010, doi: 10.1038/ejcn.2010.101.

2. J. Chakravorty, S. Ghosh, and V. B. Meyer-Rochow, "Practices of entomophagy and entomotherapy by members of the Nyishi and Galo tribes, two ethnic groups of the state of Arunachal Pradesh (NorthEast India)," J. Ethnobiol. Ethnomed., vol. 7, no. 1, p. 5, 2011, doi: 10.1186/1746-4269-7-5.

3. J. Chakravorty, S. Ghosh, and V. B. Meyer-rochow, "Chemical Composition of Aspongopus nepalensis Westwood 1837 (Hemiptera; Pentatomidae), a Common Food Insect of Tribal People in Arunachal Pradesh (India )," Int. J. Vitam. Nutr. Res., vol. 81, no. 1, pp. 1-14, 2011, doi: 10.1024/03009831/a000050.

4. J. Chakravorty, S. Ghosh, and V. B. Meyer-Rochow, "Comparative Survey of Entomophagy and Entomotherapeutic Practices in Six Tribes of Eastern Arunachal Pradesh (India)," J. Ethnobiol. Ethnomed., vol. 9, no. 50, pp. 1-12, 2013, doi: 10.1186/1746-4269-9-50.

5. J. Chakravorty, S. Ghosh, C. Jung, and V. B. Meyer-rochow, "Nutritional composition of Chondacris rosea and Brachytrupes orientalis: Two common insects used as food by tribes of Arunachal Pradesh, India Journal of Asia-Paci fi c Entomology Nutritional composition of Chondacris rosea and Brachytrupes orientalis :," J. Asia. Pac. Entomol., vol. 17, no. 3, 2014, doi: 10.1016/j.aspen.2014.03.007.

6. J. Chakravorty, S. Ghosh, K. Megu, C. Jung, and V. B. Meyer-rochow, "Nutritional and anti-nutritional composition of Oecophylla smaragdina (Hymenoptera: Formicidae) and Odontotermes sp. (Isoptera: Termitidae): Two preferred edible insects of Arunachal Pradesh, India," J. Asia. Pac. Entomol., vol. 19, no. 3, pp. 711-720, 2016, doi: 10.1016/j.aspen.2016.07.001.

7. J. Chakravorty, "Diversity of Edible Insects and Practices of Entomophagy in India: An Overview," J. Biodiversity, Bioprospecting Dev., vol. 01, no. 03, pp. 1-6, 2014, doi: 10.4172/2376-0214.1000124.

8. F. Malaisse and G. Parent, "Chemical Composition and Energetic value of some edible Products Provides by hunting or gathiring in the open Forest (Miombo)," Geo. Eco. Trop., vol. 21, no. 1-4, pp. 65-71, 1997.

9. M. G. Paoletti et al., "Nutrient Content of Termites (Syntermes soldiers) consumed by Makiritare Amerindians of the Alto Orinoco of Venezuela," Ecol. Food Nutr., vol. 42, pp. 173-187, 2003, doi: 10.1080/036702403902-2255.

10. M. G. Paoletti, Ecological Implications of Minilivestock, First Edit. Science Publishers, Inc. Enfield, New Hampshire, USA, 2005.

11. W. Sribandit, D. Wiwatwitaya, S. Suksard, and J. Offenberg, "The importance of weaver ant (Oecophylla smaragdina Fabricius) harvest to a local community in Northeastern Thailand The importance of weaver ant ( Oecophylla smaragdina Fabricius ) harvest to a local community in Northeastern Thailand," Asian MyrmecologyAsian Myrmecology, vol. 2, pp. 129-138, 2008. 
12. M. Raza, S. Jugli, and J. Chakravorty, "In-vitro antioxidant activity in edible insects from Arunachal Pradesh, India," J. Exp. Zool. India, vol. 23, no. 1, pp. 545-552, 2020, [Online]. Available: https://www.cabdirect.org/cabdirect/abstract/20203130971\%0A.

13. J. Moore and L. Yu, "Methods for Antioxidant Capacity Estimation of Wheat and Wheat-Based Food Products," in Wheat Antioxidants, no. 2, 2008, pp. 118-172.

14. M. S. Blois, "Antioxidant determinations by the use of a stable free radical," Nature, vol. 181, no. 4617, pp. $1199-1200,1958$, doi: 10.1038/1811199a0.

15. M. Oyaizu, "Studies on products of browning reaction. Antioxidative activities of products of browning reaction prepared from glucosamine.," Japanese J. Nutr. Diet., vol. 44, no. 6, pp. 307-315, 1986, doi: 10.5264/eiyogakuzashi.44.307.

16. P. Prieto, M. Pineda, and M. Aguilar, "Spectrophotometric quantitation of antioxidant capacity through the formation of a phosphomolybdenum complex: Specific application to the determination of vitamin E," Anal. Biochem., vol. 269, no. 2, pp. 337-341, 1999, doi: 10.1006/abio.1999.4019.

17. V. L. Singleton, O. Rudolf, and R. M. Lamuela-Raventos, "Analysis of Total Phenols and Other Oxidation Substrates and Antioxidants by Means of Folin-Ciocalteu Reagent," Method Enzymol., vol. 299, no. 1974, pp. 152-178, 1965.

18. C. C. Chang, M. H. Yang, H. M. Wen, and J. C. Chern, "Estimation of total flavonoid content in propolis by two complementary colometric methods," J. Food Drug Anal., vol. 10, no. 3, pp. 178-182, 2002, doi: 10.38212/2224-6614.2748.

19. E. Zielińska, M. Karaś, and A. Jakubczyk, "Antioxidant activity of predigested protein obtained from a range of farmed edible insects," Int. J. Food Sci. Technol., vol. 52, no. 2, pp. 306-312, 2017, doi: $10.1111 /$ ijfs. 13282 .

20. N. Chatsuwan, S. Nalinanon, Y. Puechkamut, B. P. Lamsal, and P. Pinsirodom, "Characteristics, Functional Properties, and Antioxidant Activities of Water-Soluble Proteins Extracted from Grasshoppers, Patanga succincta and Chondracris roseapbrunner," Hindawi J. Chem., pp. 1-11, 2018, doi: doi.org/10.1155/2018/6528312.

21. A. Islary, J. Sarmah, and S. Basumatary, "Nutritional value, phytochemicals and antioxidant properties of two wild edible fruits (Eugenia operculata Roxb. and Antidesma bunius L.) from Assam, North-East India," Med. J. Nutrition Metab., vol. 10, no. 1, pp. 29-40, 2017, doi: 10.3233/MNM-16119.

22. G. Tsiba, J. E. Yoca, M. Blondy, A. Thimoleon, and P. Ongoka, "Chemical Characterization and AntiRadical Activity of Fruits and Vegetables Commonly Consumed in Brazzaville," Food Nutr. Sci., vol. 11, pp. 773-788, 2020, doi: 10.4236/fns.2020.118055.

23. M. Saiki et al., "Analysis of Antioxidant and Antiallergic Active Components Extracted From the Edible Insect Oxya yezoensis," Nat. Prod. Commun., vol. 16, no. 5, pp. 1-6, 2021, doi: 10.1177/1934578X211023363.

24. S. J. Pyo, D. G. Kang, C. Jung, and H. Y. Sohn, "Anti-thrombotic, anti-oxidant and haemolysis activities of six edible insect species," Foods, vol. 9, no. 4, pp. 1-13, 2020, doi: 10.3390/foods9040401. 
25. J. P. Singh, A. Kaur, K. Shevkani, and N. Singh, "Composition, bioactive compounds and antioxidant activity of common Indian fruits and vegetables," J. Food Sci. Technol., vol. 53, no. 11, pp. 40564066, 2016, doi: 10.1007/s13197-016-2412-8.

26. C. Di Mattia, N. Battista, G. Sacchetti, and M. Serafini, "Antioxidant activities in vitro of water and liposoluble extracts obtained by different species of edible insects and invertebrates," Front. Nutr., vol. 6, no. July, pp. 1-7, 2019, doi: 10.3389/fnut.2019.00106.

27. D. R. Flores, L. E. Casados, S. F. Velasco, A. C. Ramírez, and G. Velázquez, "Comparative study of composition, antioxidant and antimicrobial activity of two adult edible insects from Tenebrionidae family," BMC Chem., vol. 14, no. 1, pp. 1-9, 2020, doi: 10.1186/s13065-020-00707-0.

28. H. Bin Li, K. W. Cheng, C. C. Wong, K. W. Fan, F. Chen, and Y. Jiang, "Evaluation of antioxidant capacity and total phenolic content of different fractions of selected microalgae," Food Chem., vol. 102, pp. 771-776, 2007, doi: 10.1016/j.foodchem.2006.06.022.

29. M. A. Gyamfi and Y. Aniya, "Antioxidant properties of Thonningianin A, isolated from the African medicinal herb, Thonningia sanguinea," Biochem. Pharmacol., vol. 63, pp. 1725-1737, 2002.

\section{Figures}

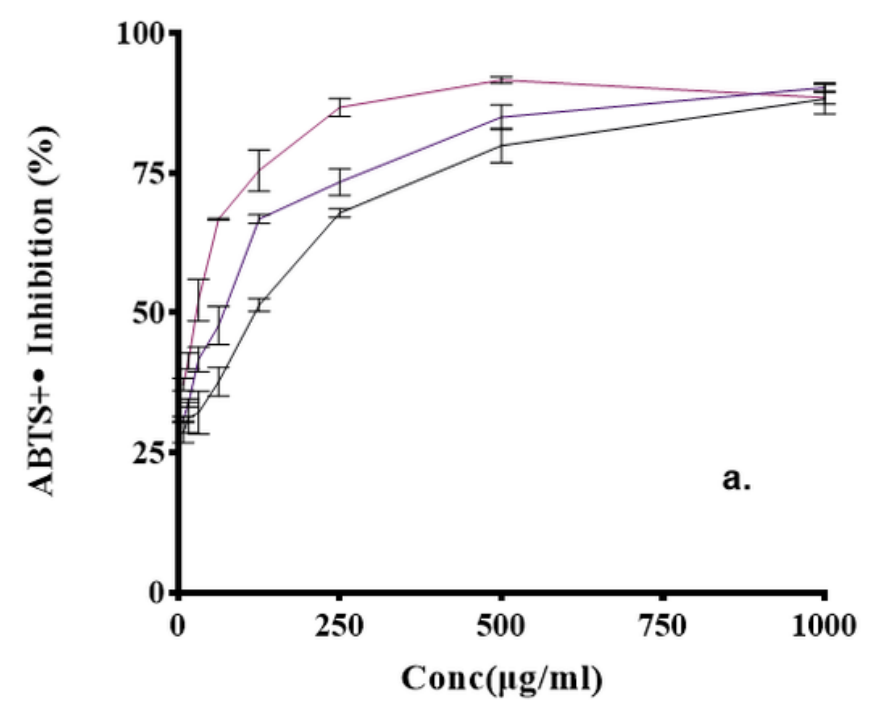

- o. smaragdina (adult)

- o. smaragdina (brood)

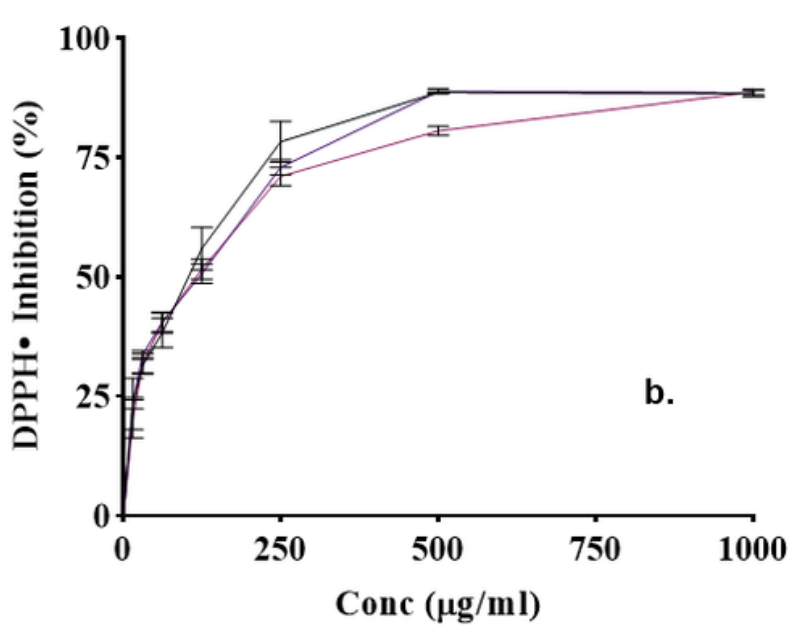

— O. smaragdina (adult) — Odontotermes sp. - O. smaragdina (brood)

\section{Figure 1}

Inhibition of (a.) ABTS+ • (b.) DPPH• free-radical of 0 . smaragdina and odontotermes sp. extracts 


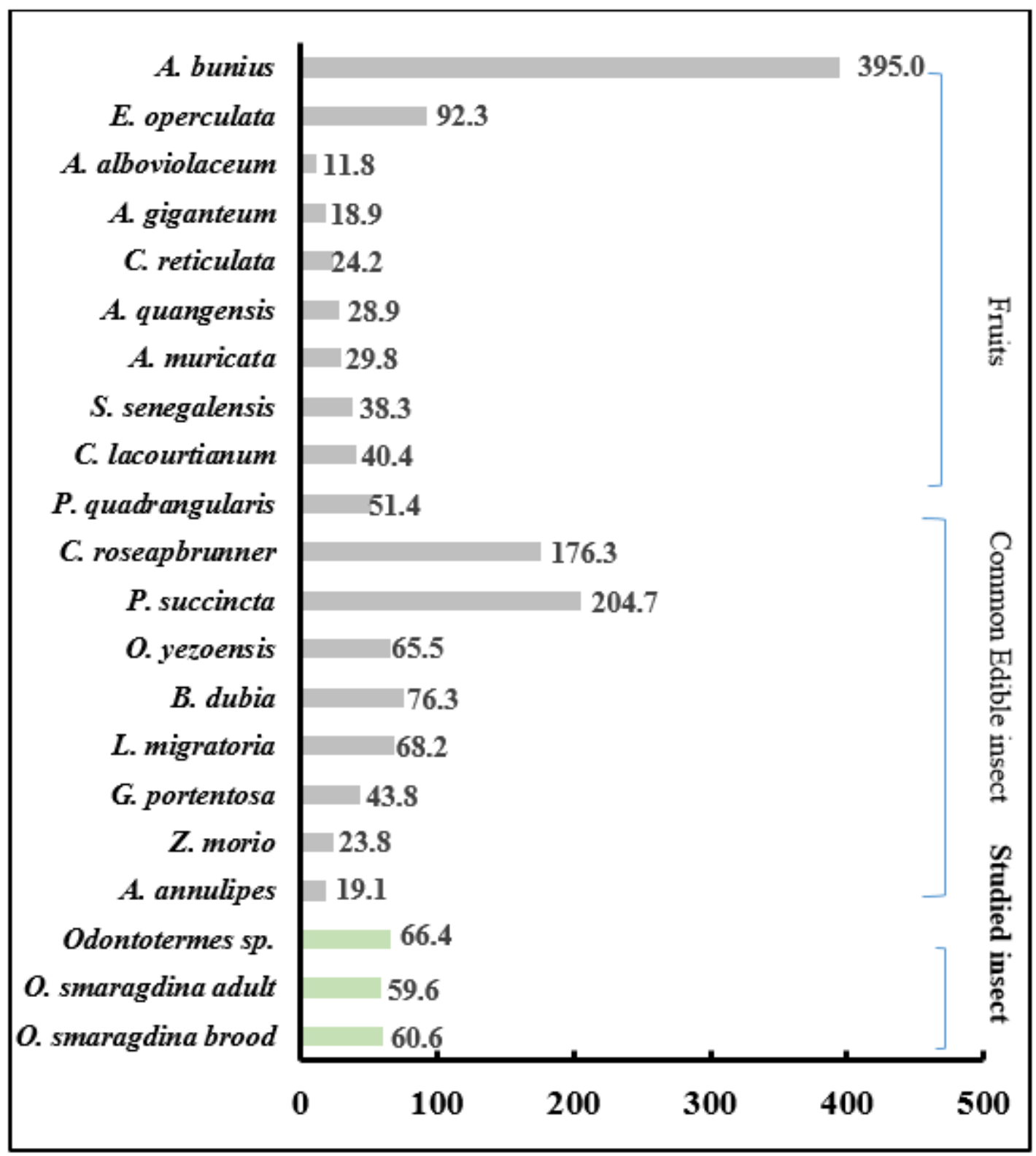

Figure 2

Comparative account of DPPH (IC50 $\mu \mathrm{g} / \mathrm{ml})$ of O. smaragdina, Odontotermes sp., conventional food of plant origin (fruit and vegetables),common edible insects (Values other than those of 0 . smaragdina and Odontotermes sp., adopted from Zielinska et al.[19], Chatsuwan et al. [20], Islary et al. [21], Tsiba et al.[22] and Saiki et al. [23] 


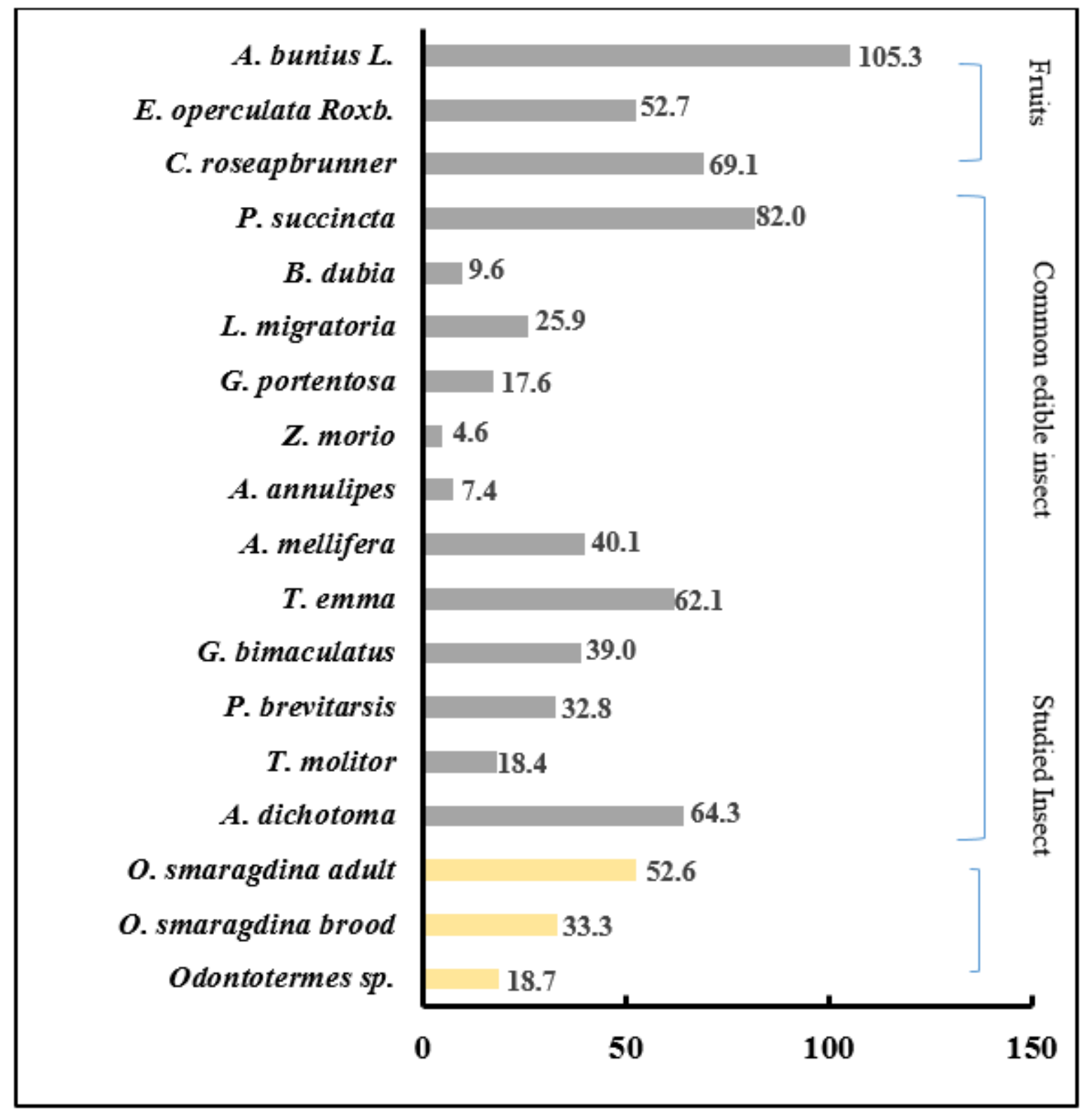

Figure 3

Comparative account of ABTS (IC50 $\mu \mathrm{g} / \mathrm{ml}$ ) of O. smaragdina, Odontotermes sp., conventional food of plant origin (fruit and vegetables), common edible insects (Values other than those of 0 . smaragdina and Odontotermes sp., adopted from Zielinska et al.[19], Chatsuwan et al. [20], Pyo et al. [24] and Islary et al. [21] 


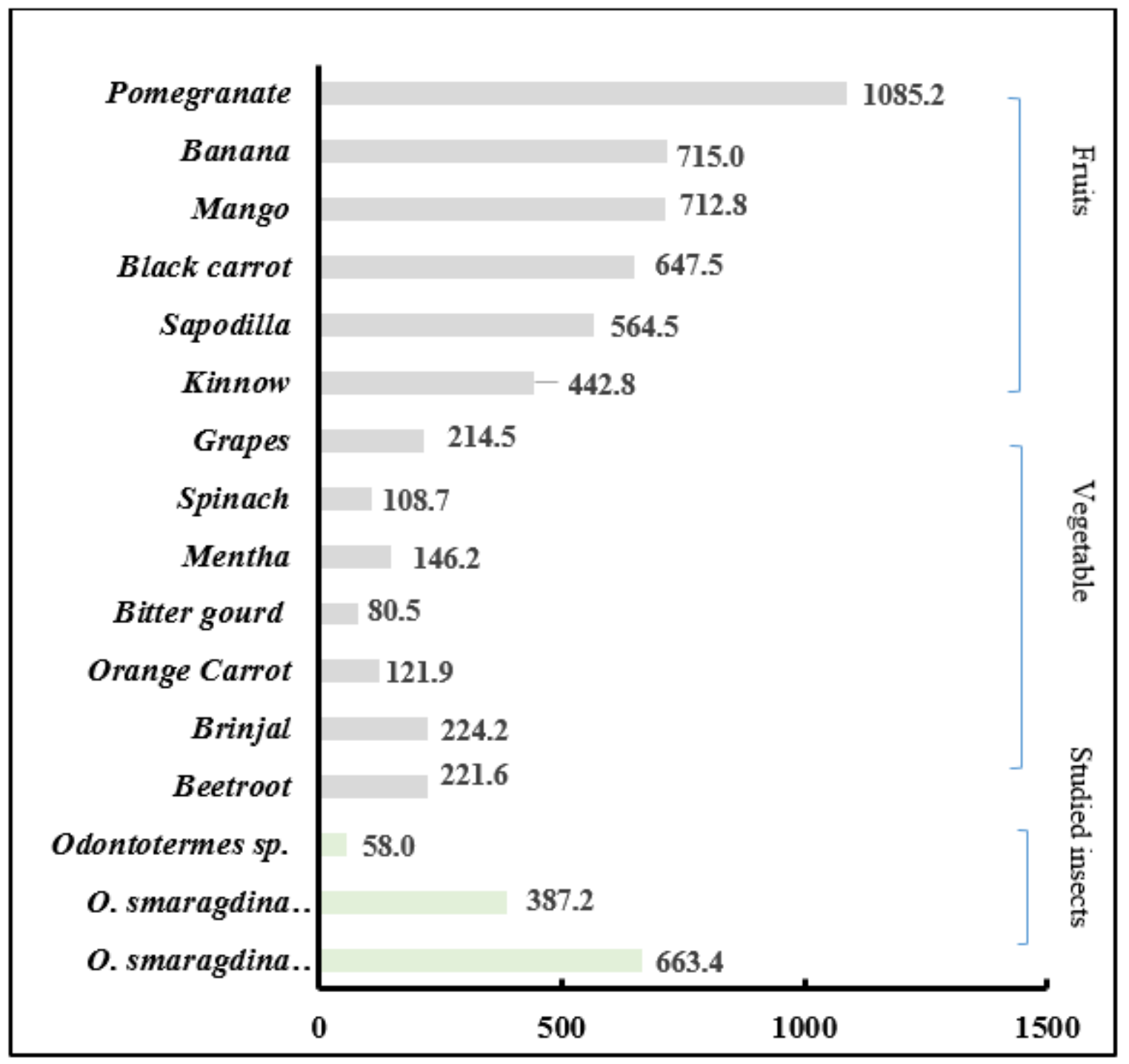

Figure 4

Comparative account of TFC content (mg RTE/100g) of O. smaragdina, Odontotermes sp., some conventional food of plant origin (fruit and vegetables) (Values other than those of 0 . smaragdina and Odontotermes sp., adopted from Singh et al. [25]. 


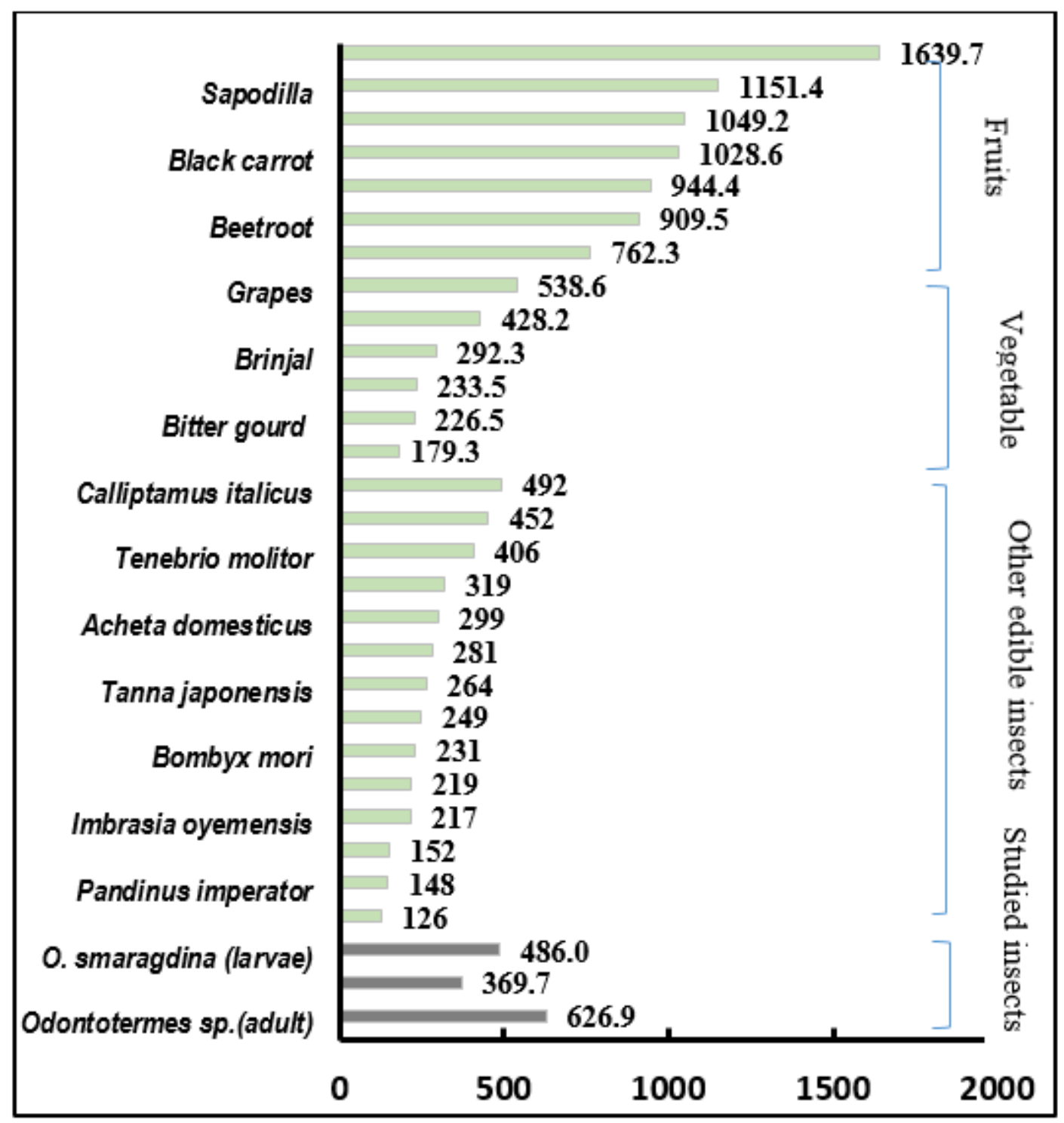

Figure 5

Comparative account of TPC (mg GAE/100g) of O. smaragdina, Odontotermes sp. ,conventional food of plant origin (fruit and vegetables), common edible insects (Values other than those of O. smaragdina and Odontotermes sp., adopted from Di-Mattia et al.[26], Flores et al. [27] and Singh et al.[25]. 